\title{
Breast milk expression knowledge of school of medicine and faculty of health sciences students
}

\author{
Nilgun Col-Araz ${ }^{1}$, Neriman Aydin ${ }^{2}$, Hatice Serap Tasdemir ${ }^{3}$, Serap Parlar-Kilic ${ }^{3}$ \\ 1. School of Medicine, Department of Pediatrics, Gaziantep University, Gaziantep, Turkey. 2. School of Medicine, \\ Department of Public Health, Gaziantep University, Gaziantep, Turkey. 3. Faculty of Health Sciences, Department of \\ Nursing, Gaziantep University, Gaziantep, Turkey \\ Correspondence: Nilgun Col Araz. Address: School of Medicine, Department of Pediatrics, Gaziantep University, \\ Gaziantep, Turkey. Email: naraz@gantep.edu.tr.
}

Received: November 27, 2012 Accepted: January 8, $2013 \quad$ Online Published: March 18, 2013

DOI : 10.5430/jnep.v3n10p19 URL: http://dx.doi.org/10.5430/jnep.v3n10p19

\section{Abstract}

Background: When direct breastfeeding of the mother's breast is not possible, expressing of human milk should be provided. Education and support to the mothers for breastfeeding by health care professionals have improved breastfeeding initiation and duration. The aim of the study was to determine the knowledge of the students of Gaziantep University School of Medicine and Faculty of Health Sciences about breast milk expression.

Methods: This questionnaire based, cross-sectional study was performed in 857 students between March 2012 and June 2012.

Results: The mean age of the participants (493 female/364 male) was $21.1 \pm 2.0$ years (16-28). The eighty-six percent (736) of the participants heard something about expression of breast milk. The majority of these students agreed that breast milk can be expressed $(642 / 736,87.2 \%)$ and stored $(595 / 736,80.8 \%)$. The seventy-six percent $(452 / 595)$ of the students stated that, glass container should be used to store the expressed milk. Most of the students $(549 / 736,74.6 \%)$ specified that breast milk expression is done by manual pump; followed by manual (277/736, 37.6\%) and by electric pump (241/736, $32.7 \%$ ). Most of the students mentioned to give the expressed breast milk with a bottle, by heating in warm water (440/595, 73.94\%; 418/595, 70.25\%; respectively).

Conclusion: These findings provide insight into the educational program of the School of Medicine and Faculty of Health Sciences for breast milk expression. The knowledge level of our students for breast milk expression is encouraging, despite inadequate experience in education programs.

\section{Key words}

Breast feeding, Breast milk expression, Education

\section{Background}

Human breast milk is recognized as the optimal infant food and provides ideal nutrition and health protection. Furthermore, the American Academy of Pediatrics (AAP) and World Health Organization (WHO) recommend that infants should be exclusively breast fed from birth until 6 months of life, and then the addition of complementary foods, with 
continued breastfeeding into toddlerhood ${ }^{[1,2]}$. When direct breastfeeding of the mother's breast is not possible, expressing of human milk should be provided ${ }^{[3]}$. If a known contraindication to breastfeeding is determined, whether this condition may be temporary, and if so expressing of breast milk may be necessary to sustain milk production ${ }^{[3]}$. In addition, premature and other high-risk-infants can be fed either by direct breastfeeding and/or the mother's own expressed milk ${ }^{[3]}$. The expression of breast milk is a significant strategy to provide mothers to maintain breastfeeding ${ }^{[4]}$. Also, recent research has shown that milk expression may increase breastfeeding duration ${ }^{[4,5]}$.

To provide an optimal environment for breastfeeding, pediatricians and other health care providers should follow this recommendation of APA: "Promote, support and protect breastfeeding excitedly" ${ }^{[3]}$. It has been shown that, education and support to mothers for breastfeeding by health care professionals have improved breastfeeding initiation and duration ${ }^{[6-9]}$.

Knowledge and opinions about breastfeeding and breast milk expression of students, who will work as health care providers in the future, may be affect breastfeeding initiation and duration. Therefore, the aim of this questionnaire based study was to determine the knowledge of the students of Gaziantep University School of Medicine and Faculty of Health Sciences about breast milk expression.

\section{Methods}

This cross-sectional study was performed in 857 students of Gaziantep University School of Medicine and Faculty of Health Sciences between March 2012 and June 2012. The questionnaire form was distributed to 912 students who attended that day at school, those do not want to participate in the study (15 students), and filled/half dropped questionnaires (40 students) were excluded. The sixty-four percent (857/1330) of all students were included in the study. Participants were informed about aim of the study and then each student completed the questionnaire form. The study was approved by the local Ethical Committee of Medical Faculty of Gaziantep University and received a written permit from the faculties.

Questionnaire: The questionnaire was prepared on the basis of the previous literature on expressing breast milk ${ }^{[3,10-12]}$. The comprehensibility of the questions was examined via a pilot study. The data from this preliminary pilot questionnaire was analyzed to develop the final version of the questionnaire. The questionnaire, which consisted of 33 questions, was divided into 2 sections: the first was related to student's socio-demographic characteristics, such as age, gender, which faculty/class, financial status, level of health insurance coverage, number of siblings, and marital status. The second section of the questionnaire was related to determine the level of student's information about breastfeeding and expression of breast milk.

Statistical Analysis: All statistical data were analyzed using the Statistical Package for the Social Sciences Program, SPSS 13.00 for Windows (SPSS Inc., Chicago IL, USA). Frequency distributions were determined, and numeric values were given as mean \pm standard deviations or case numbers were given as (\%). The chi-square test was used for comparison of categorical data. Statistical significance was determined as $p<0.05$.

\section{Results}

A total of 857 students were interviewed. The mean age of the participants (493 female/364 male) was $21.1 \pm 2.0$ years (16-28). The fifty percent (427) of the participants was student in School of Medicine, 37\% (319) of them was student in Nursing Department of Faculty of Health Sciences and 13\% (111) of them was student in Midwifery Department of Faculty of Health Sciences. Ninety-eight percent (837) of the students were single, while 2\% (20) of them were married. Six of twenty (37.5\%) students who were married had at least one child. The other socio-demographic characteristics of the students are summarized in Table 1. 
Table 1. The sociodemographic characteristics of the students

\begin{tabular}{lll}
\hline & $\mathbf{n} /$ Total & $\%$ \\
\hline Place of residence & & \\
$\quad$ The same house with his/her friends & $373 / 857$ & 43.5 \\
The students hostel & $185 / 857$ & 21.6 \\
With her/his family & $180 / 857$ & 21.0 \\
Alone at home & $91 / 857$ & 10.6 \\
$\quad$ Next to a relative & $28 / 857$ & 3.3 \\
Family's financial status & & \\
He/she can meet daily needs & $553 / 857$ & 64.5 \\
He/she can easily meet daily needs & $173 / 857$ & 20.2 \\
He/she can meet only vital needs & $104 / 857$ & 12.1 \\
He/she is unable to meet even vital needs & $27 / 857$ & 3.2 \\
Health Insurance & & \\
No & $143 / 857$ & 16.7 \\
Yes & $714 / 857$ & 83.3 \\
Employement satatus of mother's & & \\
$\quad$ Not working & $748 / 857$ & 87.3 \\
$\quad$ Working & $109 / 857$ & 12.7 \\
Employement satatus of father's & & \\
$\quad$ Working & $676 / 857$ & 79.0 \\
Retirement & $115 / 857$ & 13.4 \\
Unemployed & $66 / 857$ & 7.6 \\
\hline
\end{tabular}

The eighty-six percent (736) of the participants stated that they heard something about expression of breast milk. The majority of these students $(642 / 736,87.2 \%)$ responded to the question, why breast milk expression is to perform, "in order to feed the infant when the baby is separated from the mother" (see Table 2). Sixty-four percent (475/736) of these students agreed that mothers can continue to breast feeding when expressing of breast milk (see Table 2). Most of these students $(549 / 736,74.59 \%)$ stated that breast milk expression is done by manual pump; followed by manually $(277 / 736,37.63 \%)$ and by electric pump $(241 / 736,32.74 \%)$ (see Table 2$)$.

The majority of these 736 students $(595,80.8 \%)$, who heard something about expression of breast milk, agreed that, expressed milk could be stored. The answer of the "expressed human milk could be stored" was more likely in students of midwifery department $(p=0.000)$ (see Table 3$)$. The knowledge of participants about storage conditions of expressed breast milk are summarized in Table 3.

The $452(76.0 \%)$ of these 595 students, who agreed that expressed milk should be stored, stated that, glass container should be used to store the expressed milk. Most of them mentioned that, expressed breast milk should be given to the baby with a bottle, by heating in warm water $(440 / 595,73.94 \%$; 418/595, 70.25\%; respectively) (see Table 4).

Among the female students, the rate of hearing something about expression of breast milk was higher than male students (Female: 457/493, 92.7\% Male: 279/364, 76.6\%; $\chi^{2}=44.482, p=0.000$ ). The answer of the "expressed human milk should be stored" was more frequent by students whose mothers were working (Not working: 524/649, 80.7\%; Working: 71/87, $\left.81.6 \%, \chi^{2}=8.617, p=0.013\right)$.

No statistically significant relationship was found between the other socio-demographic characteristics and knowledge levels of students $(p>0.005)$. 
Table 2. The knowledge distribution of students about breast milk expression

\begin{tabular}{|c|c|c|c|c|c|c|c|}
\hline \multirow{2}{*}{\multicolumn{2}{|c|}{ All students }} & \multicolumn{4}{|c|}{ Faculty of Health Science } & \multirow{2}{*}{\multicolumn{2}{|c|}{ Medicine students }} \\
\hline & & \multicolumn{2}{|c|}{ Nursing students } & \multicolumn{2}{|c|}{ Midwifery students } & & \\
\hline n/total* & $\%$ & $\mathbf{n} /$ total $\dagger$ & $\%$ & n/total + & $\%$ & n/total $\|$ & $\%$ \\
\hline \multicolumn{8}{|c|}{ Why breast milk expression is to perform } \\
\hline \multicolumn{8}{|c|}{ In order to feed the infant when the baby is separated from the mother } \\
\hline $642 / 736$ & 87.2 & $248 / 284$ & 87.3 & $101 / 107$ & 94.4 & $293 / 345$ & 84,9 \\
\hline \multicolumn{8}{|c|}{ In order to feed the infant if maternal problems of the nipple } \\
\hline $477 / 736$ & 64.8 & $190 / 284$ & 66.9 & $72 / 107$ & 67.3 & $215 / 345$ & 62.3 \\
\hline \multicolumn{8}{|c|}{ In order to increase the amount of breast milk } \\
\hline $170 / 736$ & 23.1 & $63 / 284$ & 22.2 & $19 / 107$ & 17.8 & $88 / 345$ & 25.5 \\
\hline \multicolumn{8}{|c|}{ Do not know } \\
\hline $15 / 736$ & 2.0 & $8 / 284$ & 2.8 & $0 / 107$ & 0 & $7 / 345$ & 2.0 \\
\hline \multicolumn{8}{|l|}{ Others } \\
\hline $5 / 736$ & 0.7 & $4 / 284$ & 1.4 & $0 / 107$ & 0 & $1 / 345$ & 0.3 \\
\hline \multicolumn{8}{|c|}{ Can mothers continue to breast feeding when expressing of breast milk } \\
\hline \multicolumn{8}{|l|}{ Yes } \\
\hline $475 / 736$ & 64.5 & $165 / 284$ & 58.1 & $75 / 107$ & 70.1 & $235 / 345$ & 68.1 \\
\hline \multicolumn{8}{|l|}{ No } \\
\hline $78 / 736$ & 10.6 & $47 / 284$ & 16.5 & $12 / 107$ & 11.2 & $19 / 345$ & 5.5 \\
\hline \multicolumn{8}{|c|}{ Don't know } \\
\hline $183 / 736$ & 24.9 & $72 / 284$ & 25.4 & $20 / 107$ & 18.7 & $91 / 345$ & 26.4 \\
\hline \multicolumn{8}{|c|}{ How breast milk expression to do } \\
\hline \multicolumn{8}{|c|}{ By manual pump } \\
\hline $549 / 736$ & 74.6 & $203 / 284$ & 71.5 & $92 / 107$ & 86.0 & $254 / 345$ & 73.6 \\
\hline \multicolumn{8}{|c|}{ By manual } \\
\hline $277 / 736$ & 37.6 & $105 / 284$ & 37.0 & $40 / 107$ & 37.3 & $132 / 345$ & 38.3 \\
\hline \multicolumn{8}{|c|}{ By electric pump } \\
\hline $241 / 736$ & 32.7 & $86 / 284$ & 30.3 & $3 / 107$ & 2.8 & $102 / 345$ & 29.6 \\
\hline \multicolumn{8}{|c|}{ Do not know } \\
\hline $74 / 736$ & 10.1 & $30 / 284$ & 10.6 & $0 / 107$ & 0 & $41 / 345$ & 11.9 \\
\hline
\end{tabular}

Table 3. The comparison of students' opinions about breast milk expression and storage conditions

\begin{tabular}{|c|c|c|c|c|c|c|c|}
\hline \multicolumn{2}{|l|}{ Nursing } & \multicolumn{2}{|c|}{ Midwifery } & \multicolumn{2}{|c|}{ Medicine } & \multirow{2}{*}{$\chi^{2}$} & \multirow{2}{*}{$\boldsymbol{P}$} \\
\hline n/total & $\%$ & n/total & $\%$ & n/total & $\%$ & & \\
\hline \multicolumn{8}{|c|}{ Heard something about breast milk expression } \\
\hline $284 / 319$ & 89.0 & $107 / 111$ & 96.4 & $345 / 427$ & 80.8 & 21.833 & 0.000 \\
\hline \multicolumn{8}{|c|}{ Mothers can continue to breast feeding when expressing of breast milk } \\
\hline $165 / 284$ & 58.1 & $75 / 107$ & 70.1 & $235 / 345$ & 68.1 & 22.971 & 0.000 \\
\hline \multicolumn{8}{|c|}{ Expressed breast milk could be stored } \\
\hline $229 / 284$ & 80.6 & $93 / 107$ & 86.9 & $273 / 345$ & 79.1 & 26.428 & 0.000 \\
\hline \multicolumn{8}{|c|}{ Expressed breast milk can be refrigerated for 48 hours } \\
\hline $107 / 281$ & 38.1 & $33 / 107$ & 30.8 & $77 / 318$ & 24.2 & 13.502 & 0.009 \\
\hline \multicolumn{8}{|c|}{ Expressed breast milk can be frozen for up to 6 months } \\
\hline $87 / 281$ & 31.0 & $26 / 107$ & 24.3 & $51 / 318$ & 16.0 & 20.151 & 0.000 \\
\hline
\end{tabular}


Table 4. The knowledge of students for the storage and the way given of the expressed breast milk

\begin{tabular}{|c|c|c|c|c|c|c|c|c|}
\hline & \multirow{2}{*}{\multicolumn{2}{|c|}{ All students }} & \multicolumn{4}{|c|}{ Faculty of Health Science } & \multirow{2}{*}{\multicolumn{2}{|c|}{ School of Medicine }} \\
\hline & & & \multicolumn{2}{|l|}{ Nursing } & \multicolumn{2}{|c|}{ Midwifery } & & \\
\hline & n/total* & $\%$ & $\mathbf{n} /$ total $\dagger$ & $\%$ & n/total + & $\%$ & n/total $\|$ & $\%$ \\
\hline & \multicolumn{8}{|c|}{ Which container should be used for the storage of expressed breast milk } \\
\hline Plastic container & $23 / 595$ & 3.9 & $8 / 229$ & 3.5 & $8 / 93$ & 8.6 & $7 / 273$ & 2.6 \\
\hline Glass container & $452 / 595$ & 76.0 & $169 / 229$ & 73.8 & $70 / 93$ & 75.3 & $213 / 273$ & 78.0 \\
\hline Polypropylene container & $66 / 595$ & 11.1 & $27 / 229$ & 11.8 & $16 / 93$ & 17.2 & $23 / 273$ & 8.4 \\
\hline Milk storing bags & $106 / 595$ & 17.8 & $63 / 229$ & 27.5 & $10 / 93$ & 10.8 & $33 / 273$ & 12.1 \\
\hline Do not know & $77 / 595$ & 12.9 & $26 / 229$ & 11.4 & $9 / 93$ & 9.7 & $42 / 273$ & 15.4 \\
\hline \multirow[t]{2}{*}{ Others } & $2 / 595$ & 0.3 & $1 / 229$ & 0.4 & $0 / 93$ & 0 & $1 / 273$ & 0.4 \\
\hline & \multicolumn{8}{|c|}{ How expressed breast milk should be given to the baby } \\
\hline By heating on the store & $58 / 595$ & 9.5 & $24 / 229$ & 10.5 & $11 / 93$ & 11.8 & $23 / 273$ & 8.4 \\
\hline By heating in the microwave & $17 / 595$ & 2.9 & $5 / 229$ & 2.2 & $1 / 93$ & 1.1 & $11 / 273$ & 4.0 \\
\hline By heating in warm water & $418 / 595$ & 70.3 & $153 / 229$ & 66.8 & $77 / 93$ & 82.8 & $188 / 273$ & 68.9 \\
\hline Do not know & $112 / 595$ & 18.8 & $45 / 229$ & 19.7 & $7 / 93$ & 7.5 & $60 / 273$ & 22.0 \\
\hline \multirow[t]{2}{*}{ By waiting at room temperature } & $18 / 595$ & 3.0 & $11 / 229$ & 4.8 & $2 / 93$ & 2.2 & $4 / 273$ & 1.5 \\
\hline & \multicolumn{8}{|c|}{ What expressed milk should be given to the baby with } \\
\hline With a bottle & $440 / 595$ & 73.9 & $168 / 229$ & 73.4 & $75 / 93$ & 80.6 & $197 / 273$ & 72.2 \\
\hline With a spoon & $196 / 595$ & 32.9 & $88 / 229$ & 38.4 & $29 / 93$ & 31.2 & $79 / 273$ & 28.9 \\
\hline The edge of the cup & $59 / 595$ & 9.9 & $24 / 229$ & 10.5 & $3 / 93$ & 3.2 & $32 / 273$ & 11.7 \\
\hline Do not know & $61 / 595$ & 10.3 & $20 / 229$ & 8.7 & $4 / 93$ & 4.3 & $37 / 273$ & 13.6 \\
\hline Others & $1 / 595$ & 0.2 & $0 / 229$ & 0 & $0 / 93$ & 0 & $1 / 273$ & 0.4 \\
\hline
\end{tabular}

* 736 of all students who had heard something about expressing breast milk; $\uparrow 284$ of nursing students who heard something about expressing breast milk; $\$ 107$ of midwifery students who heard something about expressing breast milk; || 345 of school of medicine students who heard something about expressing breast milk

\section{Discussion}

The importance of breastfeeding is increasingly emphasized world widely. Health experts recognize that breast milk is ideal nutrition for infants, however not all infants can feed at the breast. Therefore, the expression of breast milk is important for the initiation and continuation of breastfeeding. Health care professionals have a major role in breastfeeding strategy. The aim of this study was to determine the knowledge level of the students of School of Medicine and Faculty of Health Sciences about breast milk expression. According to the current knowledge, the present study is the first to investigate the knowledge about breast milk expression of students who will work as health care professionals in the future.

In the present study, $86 \%$ of all students stated that they heard something about expression of breast milk, and $80.8 \%$ of them said that, it could be stored. The great majority of these students $(87.2 \%)$ agreed that breast milk is expressed in order to feed the infant when the baby is separated from the mother. Breastfeeding is superior to all other feeding regimens. When direct breastfeeding is not possible, infants should be fed with the mother's expressed milk ${ }^{[3]}$. Breast milk is expressed for various reasons. The most frequently reason for expressing milk is to allow someone to feed the infant with expressed breast milk, when the baby is separated from the mother. Infants are routinely fed with the mother's own expressed milk in some special cases such as prematurity, multiple gestation birth and mother return to work ${ }^{[12-15]}$.

In the recent Infant Feeding Practices Study II, 85\% of breastfeeding mother's with healthy infants expressed their milk at sometime at 1.5-4.5 months after delivery ${ }^{[12]}$. Win et al demonstrated that, whoever expressed their milk was less likely to discontinue breastfeeding before 6 months, compared with those mothers who never did any expression ${ }^{[4]}$. Obese women are reported to try more likely milk expression and to express less likely milk successfully. In addition overweight or obesity is associated with a shorter duration of breast milk production only in women who never expressed milk ${ }^{[16]}$. 
Postpartum return to work of mothers before their infants are 12 months old is associated with shorter breastfeeding duration ${ }^{[17]}$. However, maternal employment strongly predicts breast milk expression ${ }^{[18]}$. There is a trend towards increasing employment of mothers, therefore breast milk expression will play a more important role ${ }^{[4]}$. The expression of breast milk allows the mothers to be away intermittently from their infants while continuing to breastfeed ${ }^{[4]}$. An extra readily supply of breast milk may maintain an extended duration of breast feeding ${ }^{[12]}$.

In a study from O'Connor et al, 31.0\% of the physicians (pediatricians, family medicine, obstetrics/gynecology and others) recommended to discontinue breastfeeding, when there are maternal problems such as Candida infection of the nipple, mastitis, or blocked milk duct ${ }^{[19]}$. However, considering that this condition is temporary, breast milk should be expressed in such cases to maintain milk production ${ }^{[3]}$. Helling et al demonstrated that, there was an intense agreement (95.3\%) about their role as nurse-midwives practitioners to recommend breastfeeding to the mothers ${ }^{[10]}$. Encouragement of breastfeeding, supportive hospital policies, and education by healthcare professionals improved breastfeeding initiation and duration ${ }^{[6-9]}$. Knowledge and opinions about breastfeeding and breast milk expression of health care providers may affect trends in breastfeeding.

Breast pumps are widely used for expressing of breast milk ${ }^{[11,12]}$. Near-exclusive breastfeeding is associated with "use of breast pump" in the first 6 months of infant's life ${ }^{[20]}$. In our study, most of the students stated that breast milk expression is done by manual or electrical pump (74.6\% and $32.7 \%$ respectively). Family support, positive attitudes toward breast pumping, and anticipation of breastfeeding are reported to support the maintenance of breast milk production ${ }^{[14]}$. Electric pumps are the most widely used method for expressing milk, followed by manual pumps ${ }^{[12]}$. Expression of breast milk with pump is an effective strategy for maintaining breastfeeding but it is less effective than directly feeding the infant ${ }^{[11]}$. The use of double electric breast pump produces a greater and earlier amount of milk, than the use of manual breast milk expression ${ }^{[21]}$. Simultaneous pumping is more effective for producing milk than sequential pumping and breast massage has an additive effect improving milk production ${ }^{[13]}$. If there is a problem with the suck of babies, mothers should be advised to express their milk with electric pumps for the continuation of breastfeeding. In this study despite the high level of knowledge about breast milk expression in our students, our education system does not contain practicing on this issue. Helling et al. showed that, only $13.2 \%$ of nurse practitioners/nurse-midwives had done to teach women to use a breast pump in their educational program ${ }^{[10]}$. However it is known that, nurse practitioners and midwives have an important role to teach breastfeeding in their practices. To promote and support breastfeeding may be one of the most beneficial activities they can perform ${ }^{[1]}$.

The vast majority of the students thought that the expressed milk may be stored in refrigerator and freezer. They stated that expressed breast milk should be given to the baby with a bottle by heating in the warm water. It is known that, glass or plastic containers should be used to store milk, and milk should be refrigerated and then used within 48 hours. Expressed breast milk can be frozen and used for up to 6 months. Milk should be thawed rapidly by holding under tepid water and used completely within 24 hours after thawing and should not be micro waved ${ }^{[22]}$. It is very pleasure that most of our students have accurate information about this issue, but the continuity of education and the necessity of practical exercises should not be ignored.

\section{Conclusion}

These findings provide insight into the educational program of the School of Medicine and Faculty of Health Sciences for breast milk expression. It appears that our students are prepared to support mothers for expression of breast milk. However, despite this positive finding, they have inadequate experience in education programs. Our results can be useful to make some changes in educational programs and hospital practices for supporting the mothers to express breast milk for their infants. 


\section{References}

[1] Work Group on Breastfeeding. Breastfeeding and the use of human milk. American Academy of Pediatrics. Pediatrics 1997; 100: 1035-1039. PMid:9411381 http://dx.doi.org/10.1542/peds.100.6.1035

[2] World Health Organization. Infant and Young Child Feeding Model Chapter for Textbooks for Medical Students and Allied Health Professionals. WHO Pres, 2009. Available from: www.who.int/entity/child_adolescent_health/documents/9789241597494.

[3] Gartner LM, Morton J, Lawrence RA, Naylor AJ, O'Hare D, Schanler RJ, et al. American Academy of Pediatrics Section on Breastfeeding. Breastfeeding and the use of human milk. Pediatrics. 2005; 115: 496-506. PMid:15687461 http://dx.doi.org/10.1542/peds.2004-2491

[4] Win NN, Binns CW, Zhao Y, Scott JA, Oddy WH. Breastfeeding duration in mothers who express breast milk: a cohort study. Int Breastfeed J. 2006; 1: 28. PMid:17184553 http://dx.doi.org/10.1186/1746-4358-1-28

[5] Prime DK, Kent JC, Hepworth AR, Trengove NJ, Hartmann PE. Dynamics of milk removal during simultaneous breast expression in women. Breastfeed Med. 2012; 7: 100-106. PMid:22011129 http://dx.doi.org/10.1089/bfm.2011.0013

[6] Cattaneo A, Buzzetti R. Effect on rates of breast feeding of training for the baby friendly hospital initiative. BMJ. 2001; 323: 1358-1362. http://dx.doi.org/10.1136/bmj.323.7325.1358

[7] Renfrew MJ, Craig D, Dyson L, McCormick F, Rice S, King SE, et al. Breastfeeding promotion for infants in neonatal units: a systematic review and economic analysis. Health Technol Assess. 2009; 13: 1-146. PMid:19728934

[8] Kramer MS, Chalmers B, Hodnett ED, Sevkovskaya Z, Dzikovich I, Shapiro Set al: PROBIT Study Group (Promotion of Breastfeeding Intervention Trial). Promotion of Breastfeeding Intervention Trial (PROBIT): a randomized trial in the Republic of Belarus. JAMA. 2001; 285: 413-420. PMid:11242425 http://dx.doi.org/10.1001/jama.285.4.413

[9] Taveras EM, Li R, Grummer-Strawn L, Richardson M, Marshall R, Rêgo VH, et al. Opinions and practices of clinicians associated with continuation of exclusive breastfeeding. Pediatrics. 2004; 113: e283-290. PMid:15060254 http://dx.doi.org/10.1542/peds.113.4.e283

[10] Hellings P, Howe C. Assessment of breastfeeding knowledge of nurse practitioners and nurse-midwives. J Midwifery Womens Health. 2000; 45: 264-270. http://dx.doi.org/10.1016/S1526-9523(00)00010-6

[11] Fein SB, Mandal B, Roe BE. Success of strategies for combining employment and breastfeeding. Pediatrics Suppl 2. 2008; 122: S56-62.

[12] Labiner-Wolfe J, Fein SB, Shealy KR, Wang C. Prevalance of breast milk expression and associated factors. Pediatrics. 2008; 122; 63-68. PMid:18829833 http://dx.doi.org/10.1542/peds.2008-1315h

[13] Jones E, Dimmock PW, Spencer SA. A randomised controlled trial to compare methods of milk expression after preterm delivery. Arch Dis Child Fetal Neonatal Ed. 2001; 85: F91-95. PMid:11517200 http://dx.doi.org/10.1136/fn.85.2.F91

[14] Sisk P, Quandt S, Parson N, Tucker J. Breast milk expression and maintenance in mothers of very low birth weight infants: supports and barriers. Hum Lact. 2010; 26: 368-375.

[15] Geraghty SR, Khoury JC, Kalkwarf HJ. Human milk pumping rates of mothers of singletons and mothers of multiples. J Hum Lact. 2005; 21: 413-420. PMid:16280557 http://dx.doi.org/10.1177/0890334405280798

[16] Leonard SA, Labiner-Wolfe J, Geraghty SR, Rasmussen KM. Associations between high prepregnancy body mass index, breast-milk expression, and breast-milk production and feeding. Am J Clin Nutr. 2011; 93: 556-563. PMid:21209224 http://dx.doi.org/10.3945/ajcn.110.002352

[17] Scott JA, Binns CW, Oddy WH, Graham KI. Predictors of breastfeeding duration: evidence from a cohort study. Pediatrics. 2006; 117: e646-655. PMid:16585281 http://dx.doi.org/10.1542/peds.2005-1991

[18] Geraghty S, Davidson B, Tabangin M, Morrow A. Predictors of breastmilk expression by 1 month postpartum and influence on breastmilk feeding duration. Breastfeed Med. 2012; 7: 112-117. PMid:21777073 http://dx.doi.org/10.1089/bfm.2011.0029

[19] O'Connor ME, Brown EW, Lewin LO. An Internet-based education program improves breastfeeding knowledge of maternal-child healthcare providers. Breastfeed Med. 2011; 6: 421-427. PMid:21029021 http://dx.doi.org/10.1089/bfm.2010.0061

[20] Dabritz HA, Hinton BG, Babb J. Maternal hospital experiences associated with breastfeeding at 6 months in a northern California county. J Hum Lact. 2010; 26: 274-285. PMid:20484659 http://dx.doi.org/10.1177/0890334410362222

[21] Slusher TM, Slusher IL, Keating EM, Curtis BA, Smith EA, Orodriyo E, et al. Comparison of maternal milk (breastmilk) expression methods in an African nursery. Breastfeed Med. 2012; 7: 107-111. PMid:21740276 http://dx.doi.org/10.1089/bfm.2011.0008

[22] Stettler, N, Bhatia, J, Parish, A, and Stallings, VA. Feeding healthy infants, children and adolescents. In Nelson Textbook of Pediatrics. RM. Kliegman, BF. Stanton, J. St. Geme, NF. Schor, and RE. Behrman, eds. Philadelphia: Saunders, Elsevier. 2011: 160-170. http://dx.doi.org/10.1016/B978-1-4377-0755-7.00042-7 